\title{
Siderophores as an iron source for Prochlorococcus in deep chlorophyll maximum layers of the oligotrophic ocean
}

\author{
(D) Shane L. Hogle ${ }^{1,2, *}$, (D) Thomas Hackl1,3, (D)Randelle M. Bundy ${ }^{4}$, Jiwoon Park ${ }^{4}$, (D) Brandon Satinsky ${ }^{1}$, \\ (i) Teppo Hiltunen ${ }^{2}$, (D) Steven Biller ${ }^{1,5}$, (D) Paul M. Berube ${ }^{1}$, (D) Sallie W. Chisholm ${ }^{1,6^{*}}$ \\ ${ }^{1}$ Massachusetts Institute of Technology, Dept. of Civil and Environmental Engineering, Cambridge, MA, \\ USA \\ ${ }^{2}$ Department of Biology, University of Turku, Turku, Finland \\ ${ }^{3}$ Max Planck Institute for Medical Research, Biomolecular Mechanisms, Heidelberg, Germany \\ ${ }^{4}$ School of Oceanography, University of Washington, Seattle, WA, USA \\ ${ }^{5}$ Wellesley College, Biological Sciences, Wellesley, MA \\ ${ }^{6}$ Massachusetts Institute of Technology, Dept. of Biology, Cambridge, MA, USA
}

*Corresponding Authors: Shane Hogle (shane.hogle@utu.fi) and Sallie W. Chisholm (chisholm@mit.edu) 


\section{Abstract}

Prochlorococcus is one of the most abundant photosynthesizing organisms in the oligotrophic oceans. Gene content variation among Prochlorococcus populations in separate ocean basins often mirrors the selective pressures imposed by the region's distinct biogeochemistry. By pairing genomic datasets with trace metal concentrations from across the global ocean, we show that the genomic capacity for siderophore-mediated iron uptake is widespread in low-light adapted Prochlorococcus populations from iron-depleted regions of the oligotrophic Pacific and S. Atlantic oceans: Prochlorococcus siderophore consumers were absent in the N. Atlantic ocean (higher iron flux) but constituted up to half of all Prochlorococcus genomes from metagenomes in the N. Pacific (lower iron flux). Prochlorococcus siderophore consumers, like many other bacteria with this trait, also lack siderophore biosynthesis genes indicating that they scavenge exogenous siderophores from seawater. Statistical modeling suggests that the capacity for siderophore uptake is endemic to remote ocean regions where atmospheric iron fluxes are the smallest, particularly at deep chlorophyll maximum and primary nitrite maximum layers. We argue that abundant siderophore consumers at these two common oceanographic features could be a symptom of wider community iron stress, consistent with prior hypotheses. Our results provide a clear example of iron as a selective force driving the evolution of Prochlorococcus.

\section{Introduction}

Prochlorococcus is the smallest known photosynthetic organism and is among the most numerically abundant life forms on the planet. It is unicellular, free-living, geographically widespread, and highly abundant in the oligotrophic subtropical/tropical ocean, often comprising half of the total chlorophyll 1 . Prochlorococcus and its sister lineage Synechococcus account for approximately $25 \%$ of global marine net primary productivity 2 , making the picocyanobacteria key drivers of marine biogeochemical cycles 3 . Light gradients drive the vertical distribution of Prochlorococcus with low-light (LL) adapted clades occupying the deeper parts of the euphotic zone, and high-light (HL) adapted clades near the surface. This broad light-driven ecological and evolutionary division is further partitioned into mostly coherent genomic clusters (clades), each with distinct ecological and physiological properties 4]. At the finest scale of diversity, clades further partition into distinct sympatric subpopulations, which share the majority of their genes but also contain segments of unique genetic material [5. These variable regions encode functionally adaptive traits that tune each population's physiology to its local environment.

Iron $(\mathrm{Fe})$ is a crucial micronutrient for marine phytoplankton due to its central role as an enzyme cofactor in cellular processes, including respiration and photosynthesis. As a result, the concentrations and chemical forms of Fe influence global carbon cycle dynamics 6. Dissolved Fe (dFe) is scarce in much of the ocean and is mostly ( $>99 \%$ ) complexed with organic chelating ligands that solubilize and stabilize the ions in solution 7 . Concentrations of these ligands quickly increase in response to $\mathrm{Fe}$ fertilization events, which implies that they are actively produced by members of the microbial community 8. It is challenging to determine the chemical structure of these ligands 9], so their abundance and stability coefficients (a measure of how "strongly" the ligand binds $\mathrm{Fe}$ ) are typically inferred electrochemically[10. Many electrochemical studies operationally partition the ligand pool into weak $\left(\mathrm{L}_{2}\right)$ and strong $\left(\mathrm{L}_{1}\right)$ binding classes. The weak $\mathrm{L}_{2}$ class includes humic-like substances, exopolysaccharides, and undefined colloids. The strong $\mathrm{L}_{1}$ class includes siderophores, small Fe-binding molecules that microbes produce during periods of Fe starvation, but it is not clear how much of the $\mathrm{L}_{1}$ class are genuine siderophores. Under some conditions, siderophores appear to account for most of the strong $\mathrm{L}_{1}$ ligand fraction in seawater[11, 12].

There are two primary mechanisms by which marine microbes extract dFe bound to the organic ligands in the ocean. First, dFe can dissociate from organic ligands in the extracellular environment (via kinetic 
control, photodegradation, or cell surface reductases) and is imported across the outer membrane as an unbound, inorganic ion 13 . Second, whole Fe-ligand complexes can be directly translocated across cell membranes (Fig. S1) 14. Direct uptake pathways are prevalent in fast-growing copiotrophic marine bacteria with large genomes but absent in free-living marine bacteria with streamlined genomes such as Prochlorococcus or SAR11[15, 16. In these organisms, selection favors the minimization of genome size and metabolic complexity over the versatility of maintaining multiple direct Fe uptake pathways 15 . A decade ago, it was believed that Prochlorococcus fulfilled its Fe requirements only via the disassociation mechanism while relying upon a single inner membrane Fe(III) ATP-binding cassette transporter 17, 18]. Prior work also showed that Prochlorococcus isolate genomes lacked the genes necessary for siderophore biosynthesis and uptake 18 . This image changed when putative siderophore uptake gene clusters were identified from a handful of genomes from Prochlorococcus surface clades HLII and HLIV collected from remote, low-Fe regions of the global ocean 16, 19. This exciting finding suggested that some

Prochlorococcus populations had adapted to Fe scarcity by supplementing the uptake of dissociated dFe ions with the direct uptake of siderophore-bound Fe.

Siderophore uptake genes from cells belonging to HL-adapted Prochlorococcus clades have been shown to be most abundant in surface waters that have low modeled Fe concentrations 20, 21. However, extent of siderophore uptake potential in cells belonging to LL-adapted clades which are uniquely adapted to waters deep in the euphotic zone is unknown. This is important because interactions between Fe and light limitation or Fe-light co-limitation may increase Fe demand for Prochlorococcus clades inhabiting deeper waters and the deep chlorophyll maximum layer $(\mathrm{DCM})$ 22, 23. Also of interest is understanding what environmental features, in addition to Fe, are associated with Prochlorococcus siderophore uptake. Here we survey an extensive data set of picocyanobacterial uncultivated single-cell and cultivated isolate genomes to obtain a general picture of the phylogenetic and biogeographic structure of picocyanobacterial siderophore traits. Next we combine biogeochemical and metagenomic time-series datasets from the Hawai'i Ocean Time-series (HOT) station ALOHA and the Bermuda Atlantic Time-series Study (BATS) station BATS 24] to more deeply understand seasonal dynamics and the depth distributions of Prochlorococcus siderophore traits in a community context. Finally, we quantify the Prochlorococcus siderophore trait in over 700 metagenomic samples from Tara Oceans 25] and GEOTRACES 24 and connect the distribution of the trait to thousands of trace metal and other biogeochemical measurements from across the world's oceans. Using these rich data, we identify environmental features associated with Prochlorococcus siderophore uptake and reveal that siderophore uptake is predominantly a feature of low-light adapted LLI clade Prochlorococcus residing near DCM layers from the lower limits of the euphotic zone. These findings reveal new regions of phytoplankton Fe stress in the global ocean and underscore light and Fe availability as key features shaping the evolution of Prochlorococcus.

\section{Materials and Methods}

The supplementary material details all protocols and methods.

Data sources: We used a collection of over 600 Prochlorococcus single-cell and isolate genomes collected from across the global ocean 26, 27, 195 surface and DCM metagenomes from Tara Oceans project 28, 480 metagenomes acquired from GEOTRACES cruises 24], and 133 metagenomes from the HOT and BATS time-series 24. Trace metal and other chemical concentrations are from the GEOTRACES Intermediate Data Product IDP2017 version 2 (accessed January 2019) [29]. Samples were from sections GA02 30, 31], GA03, GA10[32, and GP13. Biogeochemical data from the Tara Oceans project was obtained from https://doi.pangaea.de/10.1594/PANGAEA.875579. Modeled climatological dFe from the MIT Darwin model v0.1_llc90 was obtained from the Simons Collaborative Marine Atlas project (CMAP) 33. Modeled dFe was averaged over 12 months at a 0.5 degree grid in $5 \mathrm{~m}$ 
depth bins from the upper 250 meters. Metagenome sequence data and associated metagenomes with environmental variables were quality controlled as described earlier $34,35$.

Prochlorococcus cell concentrations (qPCR-calibrated) from HOT and BATS 36 were obtained from the Biological and Chemical Oceanography Data Management Office:

https://www.bco-dmo.org/dataset/3381. $\mathrm{L}_{1}$ organic Fe-binding ligand data are from previous studies at HOT and BATS $11,37,38$. Siderophore concentrations from surface waters of the North Atlantic at stations 41-62 (data not available from the DCM) and the surface and DCM at HOT are from previous studies 11, 39. The DCM was defined as the depth range of maximum chlorophyll fluorescence at HOT $(100-125 \mathrm{~m})$ and BATS $(90-135 \mathrm{~m})$. Surface was defined as all depths shallower than the DCM.

Measurements of Fe-binding ligands and siderophores: We analyzed organic Fe-binding ligand data from BATS and HOT using competitive ligand exchange adsorptive cathodic stripping voltammetry (CLE-ACSV) as described in detail elsewhere 11, 37, 40. We measured siderophore concentrations using liquid chromatography (LC) coupled to inductively coupled plasma mass spectrometry (ICP-MS) after pre-concentration via solid-phase extraction 11, 12, 41. DCM samples were from a depth range of 70-200 meters, and surface samples were within a depth range of 3-45 meters.

Comparative genomics: The steps for producing the Prochlorococcus genome phylogeny in Fig. 1 were detailed earlier 35. Siderophore transporters were identified in Prochlorococcus genomes using the TonB dependent transporter, solute binding protein FhuD, FecCD ABC permease, ABC ATPase, TonB protein, ExbB, and ExbD proton channel families as described previously 15. All Prochlorococcus genomes were searched for siderophore biosynthesis potential using antiSMASH v5.0[42], which searches for known non-ribosomal peptide synthetases and polyketide synthase siderophore biosynthesis pathways. The true proportion of genomes with the siderophore transport cluster was estimated by accounting for genome incompleteness in the single-cell genomes as described earlier 34 .

Metagenomic read classification and count processing: Metagenome reads were mapped to the MARMICRODB marine microbial database using Kaiju v1.6.0 [43 as described before 35. Reads mapping best to the TonB dependent siderophore receptor or one of 730 core Prochlorococcus gene families were retained for further analysis. The TonB dependent receptor was selected as an indicator for the presence of the entire siderophore uptake cluster because it is the longest gene in the cluster and because its sequence composition is conserved and distinct in Prochlorococcus (Fig. S2). There was no clear similarity cutoff between metagenomic reads and the receptor sequence that differentiated Prochlorococcus clades, and we did not attempt to resolve clades by the TonB receptor (Fig. S2). Receptor and core gene counts were length-normalized to the median length of the corresponding Prochlorococcus gene, then divided by the median normalized abundance of the 730 core genes.

Statistics and data analysis: Random forest regression was performed using the normalized TonB dependent receptor abundance as the response variable and a collection of 45 potential explanatory variables with the $\mathrm{R}$ package Ranger v0.12.1[44]. Hyperparameters were tuned and the model trained using nested ten-fold cross-validation, reserving $20 \%$ of the data for estimating final model performance. Signal extraction using principal component analysis (PCA) was performed on scaled and centered predictors 45 in cross-validation. All principal components (PCs) cumulatively explaining $99 \%$ of the variance in at least one training partition were retained (27 PCs total). Signal extraction was performed to ensure that model predictors were statistically independent and to circumvent the significant inter-variable correlations in the environmental data. PC importance rankings were determined in each training partition using the Boruta heuristic [46, resulting in all predictor PCs consistently performing better than random. This step buffers against overfitting the model while assessing variable importance 
relative to reference importance (i.e., noise). Boruta rankings were aggregated over the training partitions, resulting in a total of 20 PCs that, in combination, were better predictors of siderophore abundance than randomly generated data. Cumulatively, these PCs explained $97 \%$ of the variance in the original data.

After training and testing the final random forest, the original predictor variables were related to PCs using PCA loadings by taking the square of the eigenvector matrix to get the variance explained $\left(R^{2}\right)$ by each variable for each PC. All variables with an $R^{2} \geq 0.1$ with at least one of the 20 informative PCs were retained $(\mathrm{n}=26)$. These variables were then ordered by their rank contribution to predicting the distribution of Prochlorococcus siderophore consumers. Rank contribution was calculated as the sum of the variance explained by each variable across all 20 informative PCs, with each PC weighted by the relative importance obtained from the feature importance algorithm. Pearson's correlation was used to measure the strength of the linear relationship between siderophore relative abundance and each predictor variable.

Beta regression was used to model the relationship between siderophore transporter relative abundance and nitrite, DCM depth, and LLI Prochlorococcus abundance. LLI abundance was modeled as a constant additive effect while allowing the effect of nitrite to vary as a function of DCM depth. This model was selected because light-limited phytoplankton generate nitrite 47] and deeper DCMs are, presumably, more light-limited than shallower DCMs 48 . Continuous covariates were transformed to categorical covariates by binning into three roughly equally sized groups: $3.3 \mathrm{e}-4<\mathrm{Lo} \mathrm{NO} 2 \leq 4.0 \mathrm{e}-2 ; 4.0 \mathrm{e}-2<\mathrm{Md}$ $\mathrm{NO}_{2} \leq 7.3 \mathrm{e}-2 ; 7.3 \mathrm{e}-2<\mathrm{Hi} \mathrm{NO}=1.4 ; 0.12 \%<\mathrm{Lo}$ LLI $\leq 3.5 \% ; 3.5 \%<\mathrm{Md}$ LLI $\leq 9 \% ; 9 \%<\mathrm{Hi}$ LLI $\leq$ $90 \%$. Emmeans 49 v1.6.0 R package was used to estimate the magnitude and statistical significance of marginal means for each covariate in the model. The seasonal effects in time-series metagenomes were estimated using Generalized Additive Mixed Models and Linear Mixed-Effect Models with the mgcv v1.8-26 and nlme v3.1-148 libraries in R as described earlier 34.

\section{Results and discussion}

Siderophore uptake potential in picocyanobacterial genomes: We searched a collection of 687 marine Prochlorococcus and Synechococcus genomes (including cultivated isolate genomes and uncultivated single-cell genomes) for siderophore biosynthesis and siderophore uptake gene clusters. These genomes are from over 40 distinct geographic locations across the world's oceans (Fig. 1A), including the well-studied oceanographic stations ALOHA and BATS, and span the breadth of known Prochlorococcus and Synechococcus phylogenetic diversity (Fig. 1B). Samples were collected throughout the euphotic zone at depths ranging from five meters to over 200 meters depth. In agreement with previous studies, none of the Prochlorococcus and marine Synechococcus genomes contained siderophore biosynthesis gene clusters 18, 50. However, we identified 47 genomes with siderophore transport gene clusters, hereafter siderophore consumers, (Fig. S1) and they were all either found in, or isolated from remote regions spanning the oligotrophic N. and S. Pacific Ocean gyres (Fig. 1A). Synechococcus siderophore consumers were from the North Pacific subtropical gyre and polar frontal regions between $28^{\circ} \mathrm{N}$ and $37^{\circ} \mathrm{N} 26$, where surface dFe concentrations are typically low and the surface dFe inventory is depleted before the macronutrient inventory 51. The restriction of picocyanobacterial siderophore consumers to the Pacific is analogous to the strong ocean basin segregation of genomic adaptations to nitrogen and phosphorus limitation in Prochlorococcus [52 54]. Because the Pacific Ocean encompasses over $70 \%$ of Fe-limited ocean regions [55] and siderophore uptake is a form of Fe scavenging [56], together these findings suggest that Fe scarcity is an important selective pressure on picocyanobacterial genome content in the oligotrophic Pacific ocean.

We next examined the distribution of the siderophore uptake trait among clades within the marine picocyanobacterial phylogeny. It is distributed unevenly among different clades of Prochlorococcus: 2\% 
and $14 \%$ of the genomes from HLII and HLI clades of Prochlorococcus, respectively, contained these clusters, while $31 \%$ of those from LLI Prochlorococcus contained them (Fig. 1B, Fig. S1). The relative frequency of the siderophore trait increased significantly within Prochlorococcus ecotypes with lower temperature and light level optima: for example, HLI (14\%, N=89) and LLI (31\%, N=84) 4. We also identified the siderophore transport gene cluster within genomes from Synechococcus clade $5.1 \mathrm{~A}$ (37\%, $\mathrm{N}=42$ ) in subclades II, III, IV, UC-B, and CRD2, with subclades III and IV accounting for $70 \%$ of all Synechococcus siderophore consumers. Although members of Synechococcus clades do not stratify with depth like Prochlorococcus clades[57, clade 5.1A displays low-light adapted phenotypes [58] and subclades III and I (whose distribution follows clade IV) in particular are optimized for growth at low irradiance 58. One caveat to these findings is that the total number of genomes and the clade composition between ocean basins were different so the observed gene frequencies are likely biased to some extent. Still, these findings clearly hint towards genuine trends of higher siderophore consumer frequency in the pacific ocean and in the LLI Prochlorococcus clade.

Previous studies of siderophore uptake genes in Prochlorococcus have been limited to Fe-limited surface waters which are dominated by cells belonging to HL adapted clades 19 21. Our finding that potential siderophore uptake is most prevalent within the LLI clade (Fig. 1B], which thrives in deep waters, implies that picocyanobacterial siderophore use is most likely to be associated with low-light conditions. LLI Prochlorococcus is the dominant clade at DCM layers, which form near the base of the euphotic zone and are shaped by a balance between diminished light and enhanced macronutrients (N, P, Si) from deep waters. Furthermore Fe-limitation or Fe/light co-limitation is a persistent feature of this layer 22.

Phytoplankton Fe-limitation at the DCM may emerge due to the upregulation of the Fe-rich photosynthetic apparatus under low light [59, which may increase Fe demand relative to supply [6] and thus low-light Prochlorococcus clades likely require more Fe than high-light clades 23. Indeed, Prochlorococcus has relatively high photosynthetic Fe requirements under low irradiance, and there is evidence that LLI Prochlorococcus, in particular, is uniquely adapted to the low-Fe and low-light conditions typical of the DCM 23$]$. In some cases, the high Fe requirements of LLI Prochlorococcus may make them more sensitive to fluctuations in Fe concentration than eukaryotic phytoplankton 61]. Competition for inorganic dFe ions at the DCM is intense [61], and the ability to utilize siderophores may allow Prochlorococcus to reduce relative competition for Fe through niche differentiation.

Spatial and temporal patterns at two long-term ocean study sites: We further explored the Pacific/Atlantic divide and prevalence of the trait in LLI Prochlorococcus genomes by examining metagenomes from the surface, the DCM, and the bottom of the euphotic zone at Stations ALOHA and BATS. ALOHA is located in the N. Pacific subtropical gyre 62, while BATS is located in the N. Atlantic subtropical gyre. Both stations are oligotrophic, have comparable net primary productivity and carbon export [63], and are numerically dominated by Prochlorococcus and SAR11[64]. However, atmospheric iron fluxes are significantly higher at BATS compared with ALOHA 65. Siderophores, strong Fe-binding ligands $\left(\mathrm{L}_{1}\right)$, and dFe concentrations have been measured in many studies at these locations $11,37,39$. This wealth of data allowed us to examine relationships between siderophore consumers and Fe-binding ligands, total $\mathrm{dFe}$, and siderophore concentrations on seasonal time scales.

Prochlorococcus siderophore consumers were absent at BATS but constituted up to half of all Prochlorococcus genomes from DCM metagenomes at ALOHA (Fig. 2A). We could not identify one sequence similarity threshold for short metagenomic reads that distinguished Prochlorococcus outer membrane siderophore receptors by clade (Fig. S2). Instead, we estimated the clade-integrated proportion of siderophore consumers within the total Prochlorococcus population (see methods for details). The LLI clade dominates the DCM at both ALOHA and BATS $[36$ and has the highest frequency of single-cell genomes with siderophore transporters. It is not surprising then that the frequency of siderophore consumers in the total Prochlorococcus population at the DCM was strongly positively correlated with the relative abundance of the LLI clade (Fig. 2A). Siderophore consumers also followed a seasonal pattern at the ALOHA DCM, coinciding with peaks in LLI abundance in late 
summer and early fall (Fig. 2B) Fig. S3). This pattern was not present at BATS, where the trait was effectively absent.

We also found that biogeochemical patterns of $\mathrm{dFe}$ and Fe-binding ligands were inversely related to patterns of siderophore consumer abundance at stations ALOHA and BATS (Fig. 2 $\mathrm{C}$ ), Table S1). Station ALOHA had the lowest total $\mathrm{dFe}$ and lowest $\mathrm{L}_{1}$ strong ligand concentrations. The significant enrichment of siderophore consumers at the ALOHA DCM relative to the surface also coincided with a sharp decrease in total $\mathrm{L}_{1}$ concentration, likely due to biological demand and uptake. In short, Prochlorococcus siderophore consumers are only present where and when $\mathrm{dFe}$ and $\mathrm{L}_{1}$ strong ligand concentrations are lowest. The annual spring/winter Asian dust flux is the dominant new Fe source to the N. Pacific subtropical gyre 37, 51, and this annual deposition event coincides with the lowest abundance of siderophore consumers at the ALOHA DCM (Fig. 2B). Seasonal variations in Fe supply may contribute to the seasonal succession of siderophore consumers and Prochlorococcus clades 36 at the DCM in the subtropical N. Pacific.

Global patterns of Prochlorococcus siderophore uptake genes: We next examined the abundance of Prochlorococcus siderophore consumers in ocean areas not covered by the genomic and time-series metagenomic datasets described above by quantifying the abundance of Prochlorococcus siderophore consumers in metagenomes from the upper 300 meters of the global tropical and subtropical ocean. In general, results from the global metagenomic data set reinforced our findings from the time-series metagenomes (Fig. 2) and the single-cell and isolate genomes (Fig. 1). Collectively, the global metagenomes revealed: 1) a high frequency of Prochlorococcus siderophore consumers in the subtropical and tropical Pacific relative to the N. Atlantic Ocean, and 2) high frequencies of siderophore consumers at the DCM - especially oligotrophic DCMs from the Pacific Ocean from depths over 100 meters (Fig. 3). In most Pacific DCM samples, over half of Prochlorococcus cells could potentially use siderophores (assuming the gene cluster is single-copy), which implies that a significant fraction of Prochlorococcus Fe-demand at the DCM may be fulfilled by siderophores. Unexpectedly, however, we observed a high abundance of Prochlorococcus siderophore transporters in the S. Atlantic subtropical gyre (Fig. 3), where the predicted climatological mean of dFe is relatively high (Fig. 1A). For example, over $40 \%$ of Prochlorococcus genomes were apparent siderophore consumers at the DCM in the South Atlantic ocean between $5^{\circ} \mathrm{S}$ and $25^{\circ} \mathrm{S}$, consistent with recent studies suggesting Fe-deficiency and Fe-N co-limitation in this region 66, 67. Indeed, there is a persistent local minimum in $\mathrm{dFe}$ concentrations within the euphotic zone between $5^{\circ} \mathrm{S}$ and $25^{\circ} \mathrm{S}$ on GEOTRACES transect GA02 68, and the thermocline waters (approximately 200-400 meters depth) of this region are Fe-deficient relative to macronutrients [69. Most biogeochemical models predict community N-limitation in the S. Atlantic gyre 70, 71, but there are an increasing number of studies demonstrating Fe-limitation or Fe-macronutrient co-limitation in phytoplankton communities from this region 66, 67. Like the equatorial Pacific, primary productivity in the S. Atlantic gyre may be primarily sustained by rapid and efficient internal Fe recycling due to low new Fe inputs 72, 73.

The finding of abundant Prochlorococcus siderophore consumers at the DCM and in the S. Atlantic subtropical gyre led us to ask what specific chemical, biological, and hydrographic mechanisms might influence these distributions. We trained a random forest regression for Prochlorococcus siderophore consumer abundance using a set of 27 predictive features derived from PCA on a 45 variable dataset of hydrographic, geochemical, and biological measurements (see methods, supplementary material). We then ranked the original variables by their weighted contribution to explaining the variance in the 20 informative PCs (Fig. 44. The final model had excellent predictive performance in the test dataset $\left(\mathrm{R}^{2}\right.$ $=0.93$, RMSE $=0.00017$ ) indicating that the abundance of Prochlorococcus siderophore consumers can accurately be predicted from GEOTRACES and Tara Oceans biogeochemical data. Prochlorococcus siderophore consumers covaried with the biogeochemical parameters that distinguish the subtropical/tropical N. Atlantic ocean, the Mediterranean Sea, and the Red Sea from the rest of the ocean. The N. Atlantic, Mediterranean Sea, and the Red Sea have the highest salinity 74 and receive a 
large flux of atmospherically deposited material due to their proximity to the Saharan desert and the Arabian peninsula [65]. Correspondingly, salinity and atmospherically deposited trace elements - such as $\mathrm{Cu}, \mathrm{Al}, \mathrm{Zn}, \mathrm{Mn}, \mathrm{Fe}$, and $\mathrm{Pb} 75$ - were strongly negatively associated with Prochlorococcus siderophore consumers (Fig. 4 . Fig. 5 . Fig. S4). Siderophore transporters were highly abundant in a handful of equatorial Pacific samples dominated by the HLIV clade ( $>60 \%$ HLIV), which has been shown previously to have siderophore transport genes [19] and is associated with Fe-limited ocean regions 76]. Overall, our findings reveal that picocyanobacterial siderophore uptake is common in the remote reaches of the subtropical/tropical oligotrophic ocean, where the atmospheric input fluxes of trace elements to the upper ocean are smallest.

Of all trace metals in the global dataset, dFe measured from GEOTRACES samples explained most of the weighted variance across the principal component predictors used in the random forest. However, the magnitude of its linear correlation with siderophore consumers $(r=-0.10)$ was smaller than for other metals like $\mathrm{Al}(r=-0.28)$ or $\mathrm{Cu}(r=-0.28)$ (Fig. 5). Modeled dFe concentrations from the Darwin biogeochemical model were more correlated with Prochlorococcus siderophore consumers $(r=-0.54)$ than any trace metal measurement measurements of all trace metal measurements, including dFe. Although these variables each had a stronger linear relationship with siderophore consumers than with $\mathrm{dFe}$ measurements from the GEOTRACES program, dFe variance was partitioned across multiple, strongly predictive principal components (Fig. 4). This implies that dFe's predictive power in the random forest was primarily derived from its nonlinear associations and interactions with other environmental variables (e.g., LLI abundance, DCM depth, nitrite and salinity) and not its linear correlation with siderophore consumers. This is compatible with current views of marine Fe biogeochemistry: most of the upper ocean dFe inventory is cycled rapidly and shaped by multiple interacting biotic and abiotic biogeochemical processes 73$]$.

The strong linear correlation between modeled climatological mean $\mathrm{dFe}$ concentrations and Prochlorococcus siderophore consumers is likely because atmospheric dust deposition is the dominant $\mathrm{Fe}$ source to the ocean in the MIT Darwin model 77]. This mirrors the strong negative linear relationship we observe between siderophore consumers and atmospherically deposited elements (e.g., aluminum) in the GEOTRACES data and the strong partitioning of Prochlorococcus siderophore consumers to the oligotrophic Pacific and S. Atlantic. Thus, we argue that the global biogeography of Prochlorococcus siderophore consumers is driven by basin-scale geological forcing in the marine Fe cycle 75, 78.

Specifically, it appears that patterns of atmospheric dust deposition set the biogeographical boundary for where the relative fitness benefit of siderophore use exceeds that for reduced genome size and gene $\operatorname{loss} 79$. On a local scale, the fraction of a Prochlorococcus population that can use siderophores will also reflect a combination of physiological and ecological processes (e.g., light availability), which governs local dynamic biogeochemical processes like regeneration, scavenging, uptake, and colloid formation. In this way, the abundance of Prochlorococcus siderophore consumers reflects a balance of both the "fast" and "slow" biogeochemical processes shaping the marine Fe cycle.

Surprisingly, the random forest regression also showed a strong association between siderophore consumers nitrite concentrations and DCM depth. We explored this relationship further using linear regression (Fig. 6. Table S2). The results were most consistent with a scenario where Prochlorococcus siderophore consumers are abundant at depths with the highest nitrite concentrations, especially where the DCM layer is deeper than 100 meters and to a lesser degree where LLI cells are most abundant. We propose that this pattern is due to phytoplankton Fe and light limitation (or co-limitation) at the DCM and the primary nitrite maximum layer. The origin of the primary nitrite maximum is debated, but it likely forms due to incomplete assimilatory nitrate reduction by Fe- or light-limited phytoplankton 48 in parallel with uncoupled chemoautotrophic nitrification 80 . Due to fast phytoplankton uptake kinetics, nitrite should only accumulate in waters with low photon flux, where phytoplankton inorganic nitrogen uptake is limited by Fe and light 80 . Nearly all LLI cells can assimilate nitrite and some can also assimilate nitrate [54, but we found no evidence that nitrate assimilation genes were more or less abundant in LLI siderophore consumers than expected by chance. Overall, the significant positive 
association of siderophore consumers and LLI Prochlorococcus with high nitrite samples - especially with the deepest DCMs - provides indirect support for the hypothesis that the primary nitrite maximum layer in the euphotic subtropical/tropical ocean is associated with Fe and light limitation of photoautotrophic cells.

\section{Synthesis:}

High-frequency dynamics in the organic Fe-binding ligand pool of the upper ocean balance the interplay between regeneration and removal fluxes which determines the global inventory of oceanic $\mathrm{Fe}, 73,81$. Siderophores are increasingly understood to be an important molecular mechanism regenerating Fe from biomass and incorporating atmospherically deposited lithogenic Fe into microbial ecosystems 56. Many copiotrophic marine bacteria produce and use siderophores, but nearly all genome-streamlined oligotrophic marine bacteria do not - likely to minimize overall metabolic complexity 15, 16. This raises the question of how minimalist cells like Prochlorococcus fulfill their Fe requirements, especially in the most Fe-limited regions.

Using rich genomic and metagenome data sets, we found that large populations of Prochlorococcus and Synechococcus from remote regions of the global ocean have evolved the ability to scavenge exogenous siderophore-bound $\mathrm{Fe}$, which likely helps them fulfill cellular iron demand in limiting or stressful conditions. The siderophore uptake trait is prominent in ocean regions where the atmospheric Fe flux to the surface ocean is lowest (Fig. 7). In these regions, Fe recycling mediated by organic ligands fuels the majority of primary productivity 72$]$. Here siderophores are likely a critical molecular shuttle between particulate, colloidal, and dissolved phases, ultimately retaining Fe in the upper ocean (Fig. 7). The siderophore uptake trait is most abundant in picocyanobacteria inhabiting remote Fe-depleted regions and in low-light adapted Prochlorococcus, particularly those at deep DCMs near the primary nitrite maximum layer. The vertical distribution of this trait in the water column implies that light availability is also an important control on Prochlorococcus Fe demand. Indeed, the association of siderophore consumers with the highest nitrite concentrations suggests that nitrite accumulation in the euphotic zone may be a consequence of both iron and light limitation.

Our results imply that the presence of siderophore-consuming Prochlorococcus could be a valuable biomarker for diagnosing ecosystem Fe deficiency. Indeed, our study highlights two areas of potential iron-stress that warrant further investigation - the S. Atlantic subtropical gyre and the DCM of the oligotrophic Pacific and S. Atlantic oceans. These areas have historically been considered nitrogen- and light-limited ecosystems, but our results suggest an essential role for Fe. Most of the potentially Fe-deficient regions revealed by our analysis are remote, and sampling Fe at these locations requires specialized knowledge of shipboard trace metal incubations, sampling, and analysis. Because DNA sampling does not require specialized trace metal clean conditions, omics-based approaches based on robust markers of nutrient deficiency could be one complementary tool for increasing the breadth of trace metal surveys in the ocean. Here we have leveraged cross-scale biology of the well-described and ubiquitous marine picocyanobacterium, Prochlorococcus, to reveal vast regions of community iron deficiency in the global ocean using a siderophore transport system as a biomarker. These findings highlight the intricate connection between the ecology and evolution of Prochlorococcus and the Fe cycle of the surface ocean. 


\section{Data and materials availability}

GEOTRACES and HOT/BATS Metagenome sequencing reads are available from the NCBI Sequence Read Archive under studies SRP110813 and SRP109831 and BioProjects PRJNA385854 and PRJNA385855. Associated sample collection data can be found at https://dx.doi.org/10.1038/sdata.2018.176. Tara Oceans Primary Metagenome sequencing reads are available from the European Nucleotide Archive under project PRJEB402. Associated Tara Oceans chemical and environmental data are available from the Pangaea repository at https://doi.pangaea.de/10.1594/PANGAEA.875576. Chemical data from the GEOTRACES Intermediate Data Project IDP17 v2 are available at https://www.bodc.ac.uk/geotraces/data/idp2017/. Picocyanobacterial single cell genomes and other sequence data are available from GenBank 16S/ITS records MG666579-MG668595, MH074888-MH077527, MH319718-MH319767, and MH327275-MH327492; NCBI Sequence Read Archive study SRP141175; and Genbank assemblies QBVH00000000-QCVZ00000000. Associated sample collection data can be found at https://dx.doi.org/10.1038/sdata.2018.154. Output from the MIT Darwin model and qPCR measurements of Prochlorococcus abundance at HOT/BATS is available from the Simons Collaborative Marine Atlas Project https://simonscmap.com/. The MARMICRODB reference database and instructions for use are available from https://dx.doi.org/10.5281/zenodo.3520509. All computer code for reproducing the results from this specific study is available from https://github.com/slhogle/cyano-sidero-ocean.

\section{Acknowledgments}

We thank present and past members of the GEOTRACES consortium for collecting, curating, and sharing trace metal and other biogeochemical data. In particular, we thank the GEOTRACES chief scientists for their support: Andrew Bowie (University of Tasmania), Philip Boyd (University of Tasmania), Edward Boyle (Massachusetts Institute of Technology), Gregory Cutter (Old Dominion University), Loes Gerringa (NIOZ Royal Netherlands Institute for Sea Research), Gideon Henderson (University of Oxford), William Jenkins (Woods Hole Oceanographic Institution), and Micha Rijkenberg (NIOZ Royal Netherlands Institute for Sea Research), as well as Gerhard Herndl (University of Vienna), James Moffett (University of Southern California) and Hein de Baar (NIOZ Royal Netherlands Institute for Sea Research) for their support with GEOTRACES. We thank the HOT and BATS field teams and organizational leaders for their assistance. We also thank the developers, maintainers, and administrators of the Simons Collaborative Marine Atlas Project and the MIT Darwin ecosystem model. This work was supported in part by grants from the National Science Foundation (OCE-1153588, and DBI-0424599 to SWC) and the Simons Foundation (Life Sciences Project Award IDs 337262, 647135 to SWC; SCOPE Award ID 329108 to SWC. This paper is a contribution from the Simons Collaboration on Ocean Processes and Ecology (SCOPE).

\section{Author contributions}

SLH - Conceptualization, Investigation, Data curation, Software, Formal analysis, Visualization, Writing original draft, Writing review and editing; THackl - Investigation, Data curation, Software, Formal analysis, Writing review and editing; RMB - Investigation, Data curation, Methodology, Writing review and editing; JP - Data curation, Methodology, BMS - Data curation, Writing review and editing, THiltunen - Resources, Investigation, Writing review and editing; SJB - Data curation, Investigation, Writing review and editing; PB - Data curation, Investigation, Writing review and editing; SWC - 
bioRxiv preprint doi: https://doi.org/10.1101/2021.11.13.468467; this version posted November 19,2021 . The copyright holder for this preprint (which was not certified by peer review) is the author/funder, who has granted bioRxiv a license to display the preprint in perpetuity. It is made available under aCC-BY 4.0 International license.

Conceptualization, Supervision, Project administration, Resources, Funding acquisition, Writing review and editing. 


\section{Figures:}
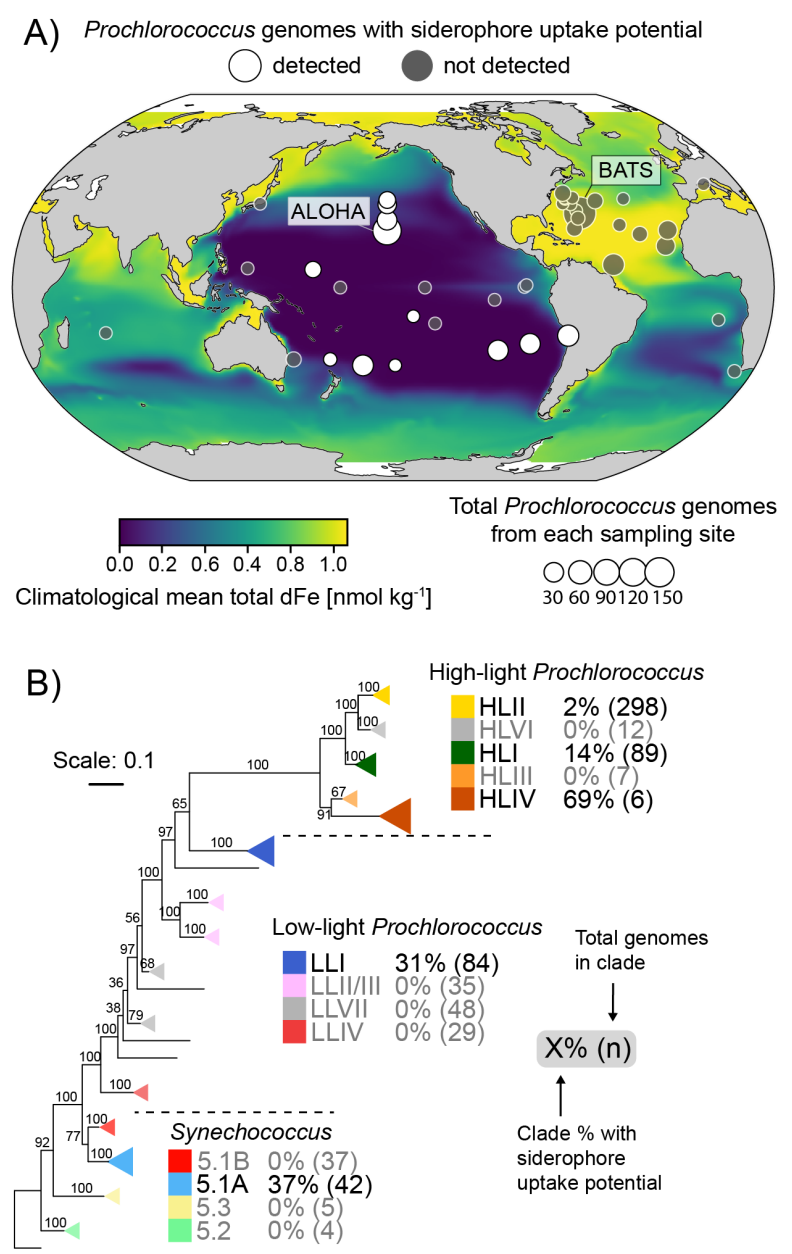

Figure 1. Phylogenetic and biogeographic patterns of picocyanobacterial siderophore consumers

A) Sampling locations of picocyanobacteria isolate and single-cell genomes used for this study. Point size is proportional to the total number of isolated genomes from each location, and point color shows whether a siderophore consumer genome was isolated at that location. Map color displays the climatological annual mean total dissolved Fe concentration nnmol kg-1 integrated over the upper 55 meters of the water column. Oceanographic stations ALOHA and BATS are denoted for reference. B) The phylogenetic tree was built with 96 Synechococcus genomes and 605 Prochlorococcus genomes and is rooted at Synechococcus sp. WH5701; nodes show bootstrap values (250 resamplings). Triangles depict monophyletic clades, and triangle area is proportional to the number of siderophore consumer genomes in each clade. 

available under aCC-BY 4.0 International license.

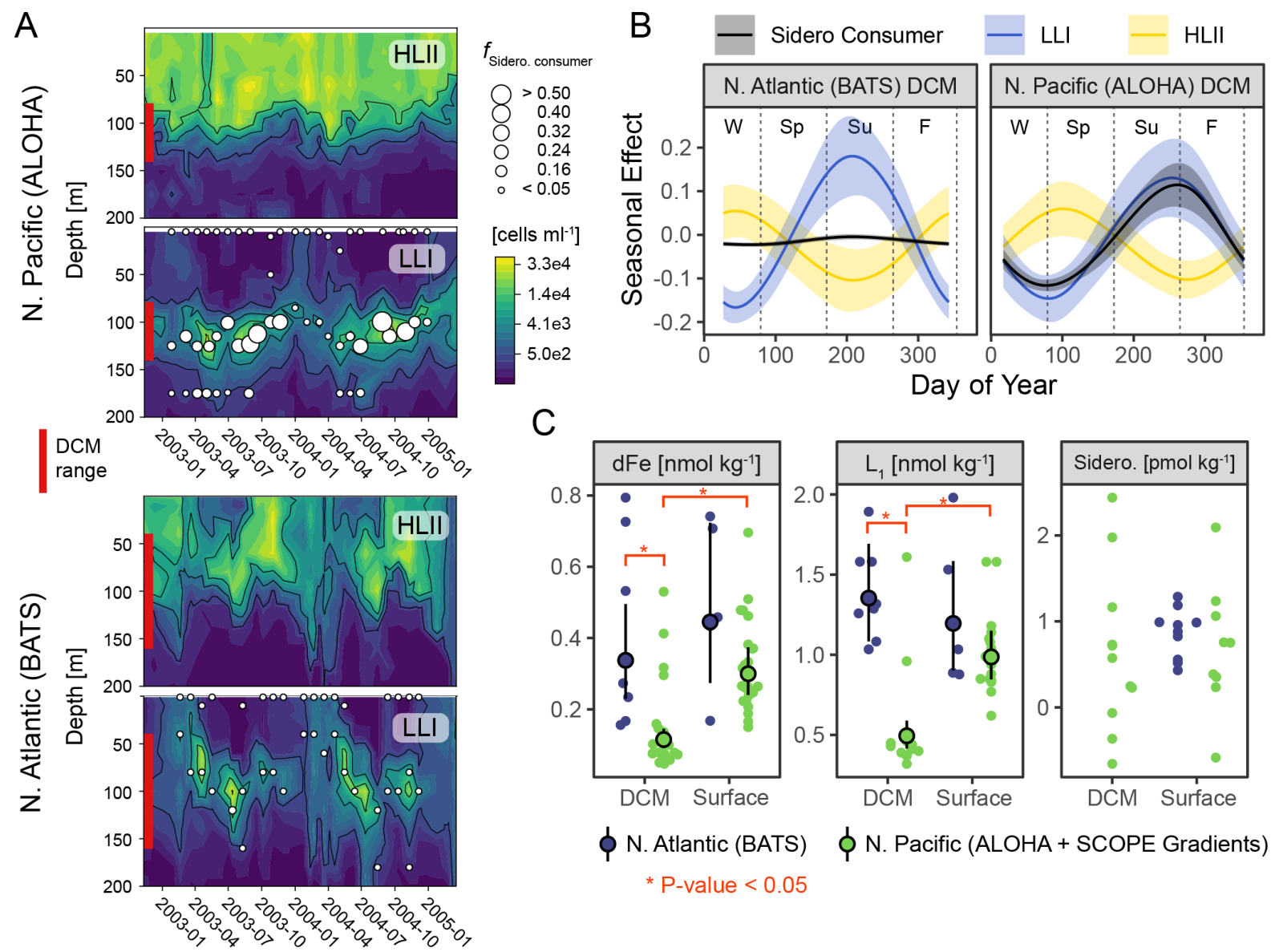

Figure 2. Siderophore consumers associate with the DCM in the N. Pacific, but not the N. Atlantic A) Prochlorococcus HLII and LLI cell density over two years at HOT and BATS as determined by qPCR 36. Contour plots of cell concentrations are cube root transformed. The deep chlorophyll maximum (DCM) depth range is highlighted in red. $f_{\text {sidero. consumer }}$ is the fraction of Prochlorococcus siderophore consumers, and point size is proportional to relative abundance. B) The modeled seasonal effect (arbitrary units) on siderophore consumers, LLI, and HLII Prochlorococcus clades at the DCM at stations BATS and HOT. C) dFe concentration, $\mathrm{L}_{1}$ strong Fe-binding ligands, and specific siderophore classes in the N. Pacific and N. Atlantic subtropical gyres. Points and error bars are marginal population means and 95\% confidence intervals from regression. Full model results are in Table $\mathrm{S} 1$. 


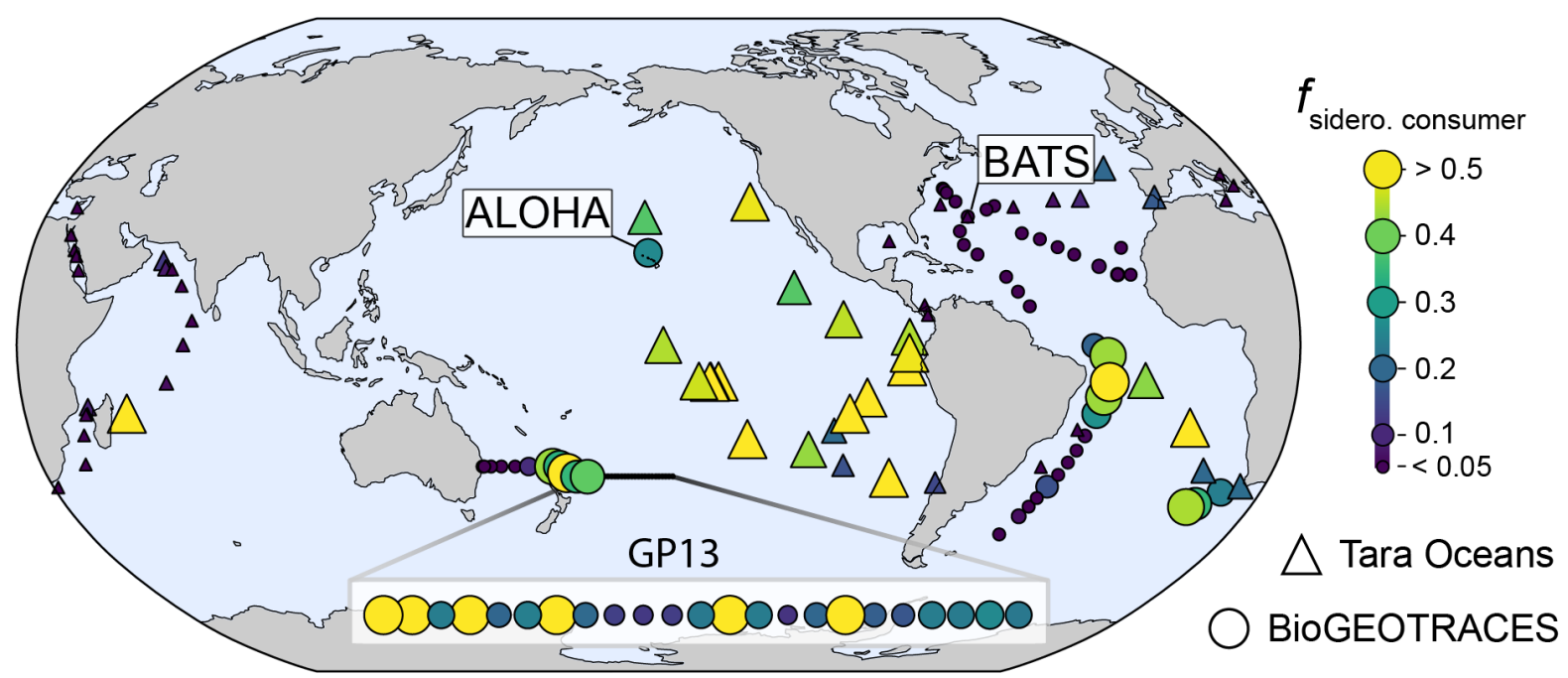

Figure 3. Global biogeography of Prochlorococcus siderophore consumers identified from metagenomes collected from deep chlorophyll maximum layers.

Frequency of Prochlorococcus genomes with siderophore uptake gene clusters $\left(f_{\text {sidero. consumer }}\right)$ at the DCM in the GEOTRACES (circles) and Tara Oceans (triangles) metagenomes. Samples from the GP13 section (S. Pacific) are expanded for increased visibility. Point color and size are proportional to siderophore trait frequency. 


\section{Variable type}

Ecotype abundance

Macronutrients/

Hydrography

Trace metals

\section{$\mathrm{R}^{2}$ between variable and $\mathrm{PC}$}

0.4

0.3

0.2

0.1

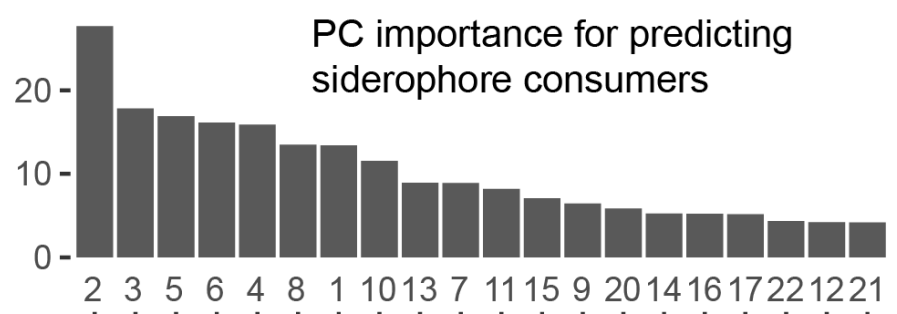

Salinit

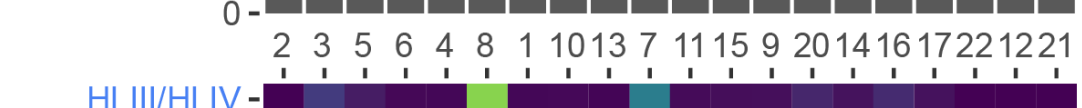

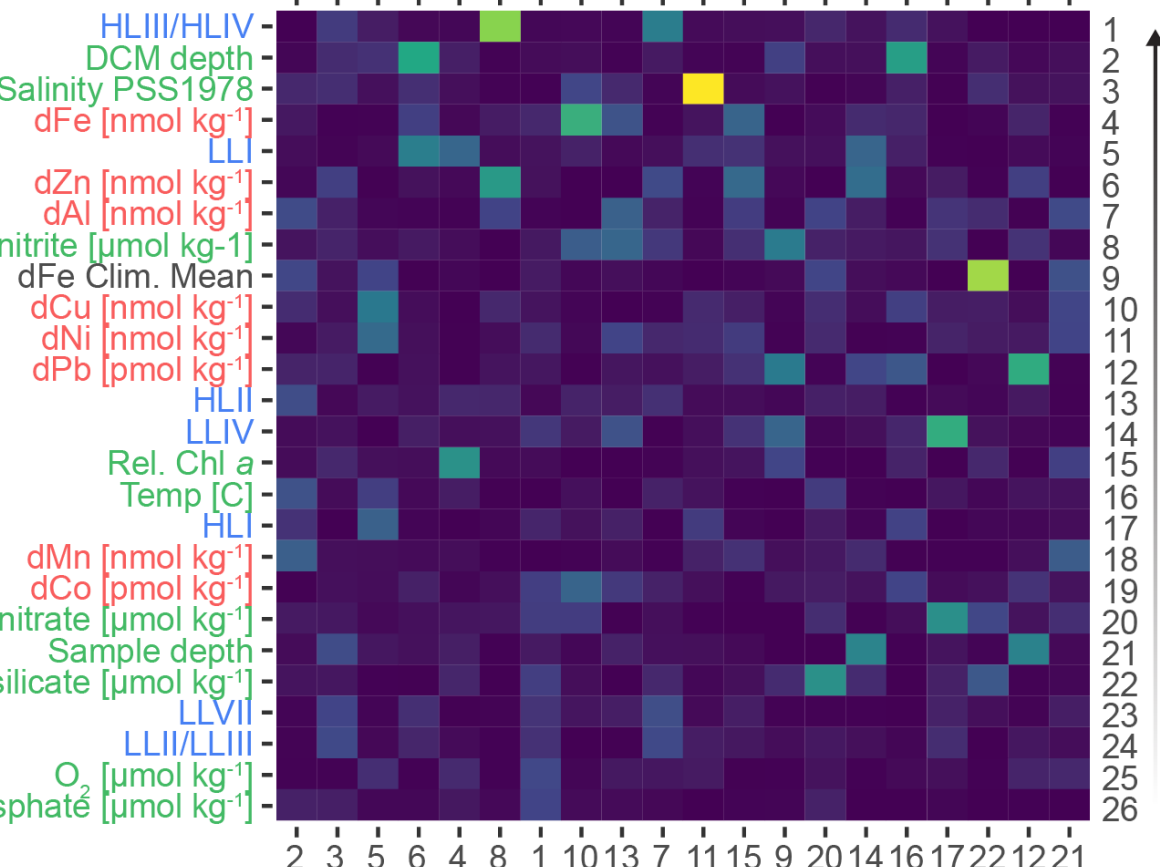

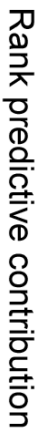

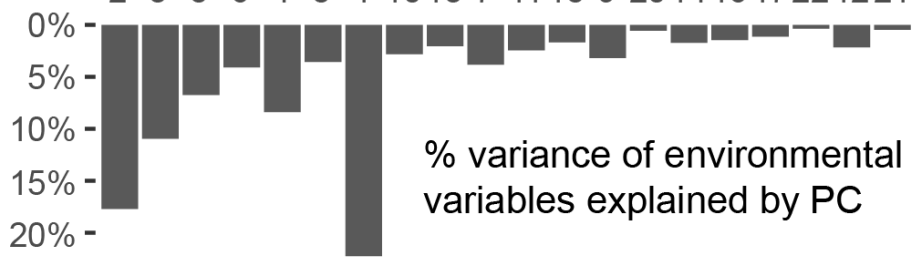

Principal component (PC)

Figure 4. Oceanographic features associated with Prochlorococcus siderophore consumers

Environmental variables (heatmap left) are colored by variable type and ordered (heatmap right) by their rank contribution to predicting the distribution of Prochlorococcus siderophore consumers (see methods). Top barplot shows the informative principal components derived from the combined dataset and ranked by their importance (unitless) to the random forest model. The lower barplot shows the $\%$ total variance explained by each of the informative principal components. Heatmap color shows the correlation $\left(R^{2}\right)$ between each variable and each informative principal component. 


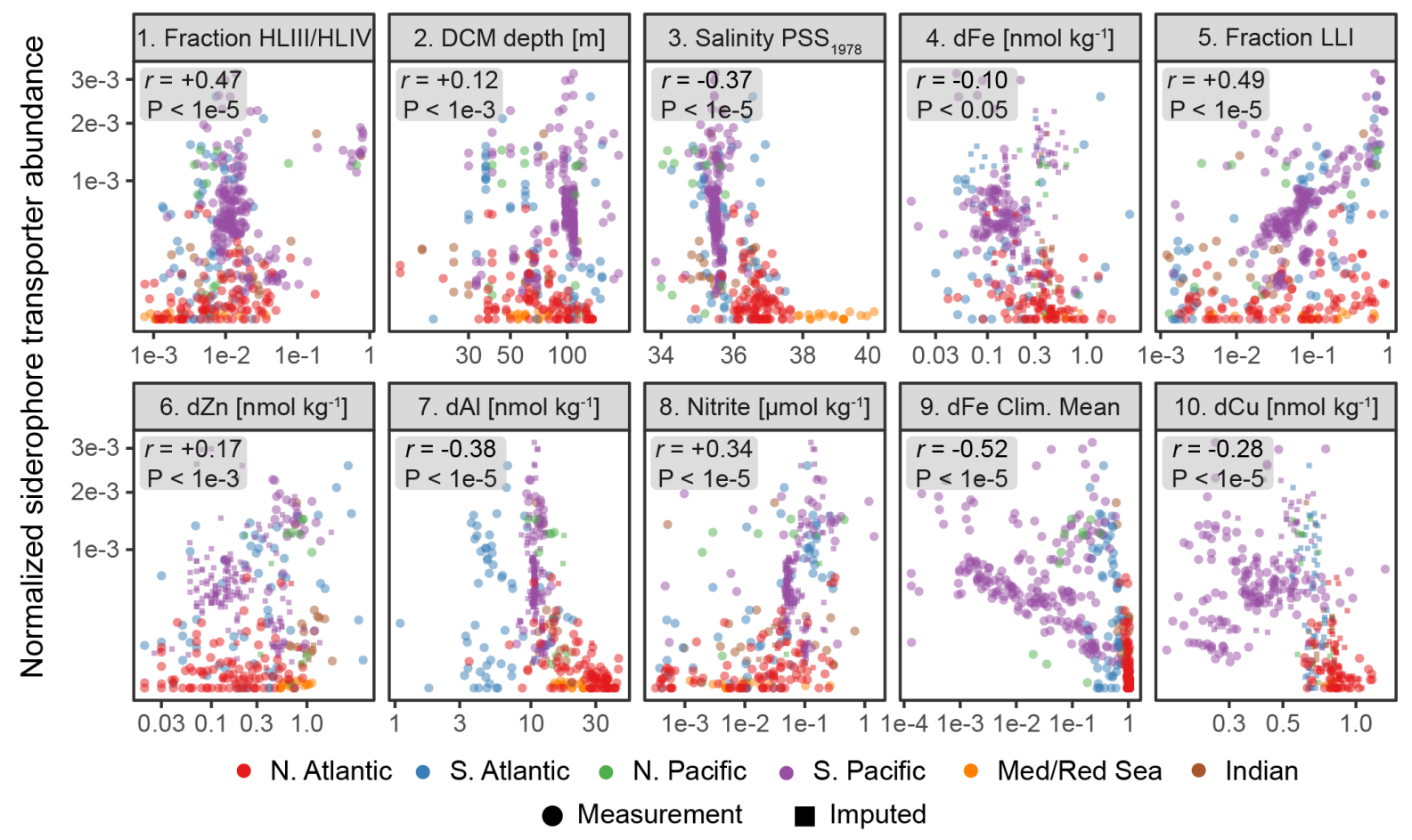

Figure 5. Top ten most predictive variables for Prochlorococcus siderophore consumer distribution These ten environmental variables (ranked 1-10) have the greatest cumulative predictive contribution to the random forest model (Fig. 4 see methods). Each point is a metagenomic observation colored by ocean basin. Small squares represent samples with missing data that was imputed (see methods). dFe climatological means are from the MIT Darwin model. The remaining measurements are in situ chemical, biological, or hydrographic measurements from GEOTRACES and Tara Oceans. Boxes show Pearsons's correlation coefficient and the p-value testing whether true $r$ is equal to 0 . 


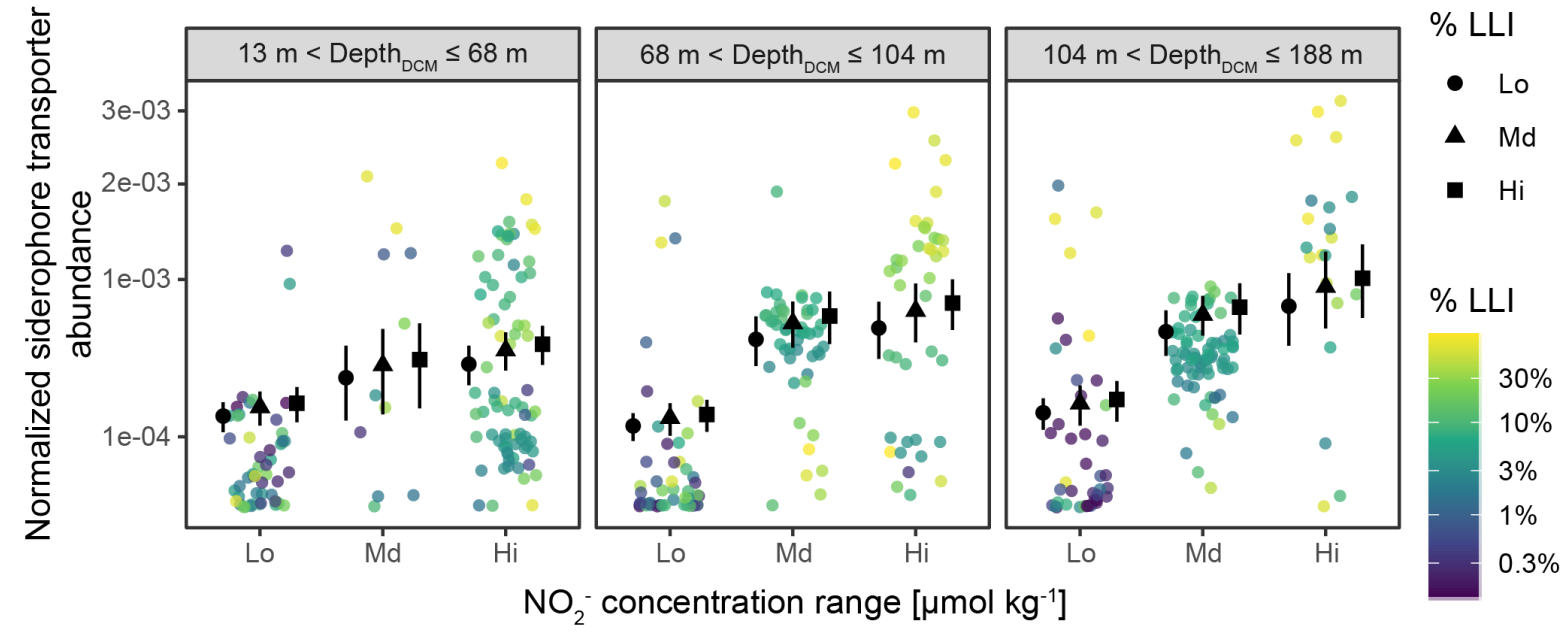

Figure 6. Prochlorococcus siderophore consumers associate with the highest nitrite concentrations and the deepest deep chlorophyll maximum layers

Each point is a direct metagenomic observation colored by the percentage of LLI clade in each sample. Subplots show different DCM depth ranges. Points and error bars show estimated marginal population means and $95 \%$ confidence intervals from beta regression using LLI \% clade abundance, nitrite concentration, and DCM depth as model covariates. These continuous covariates were transformed into categorical covariates for regression by binning into three equal-sized groups (see methods). 


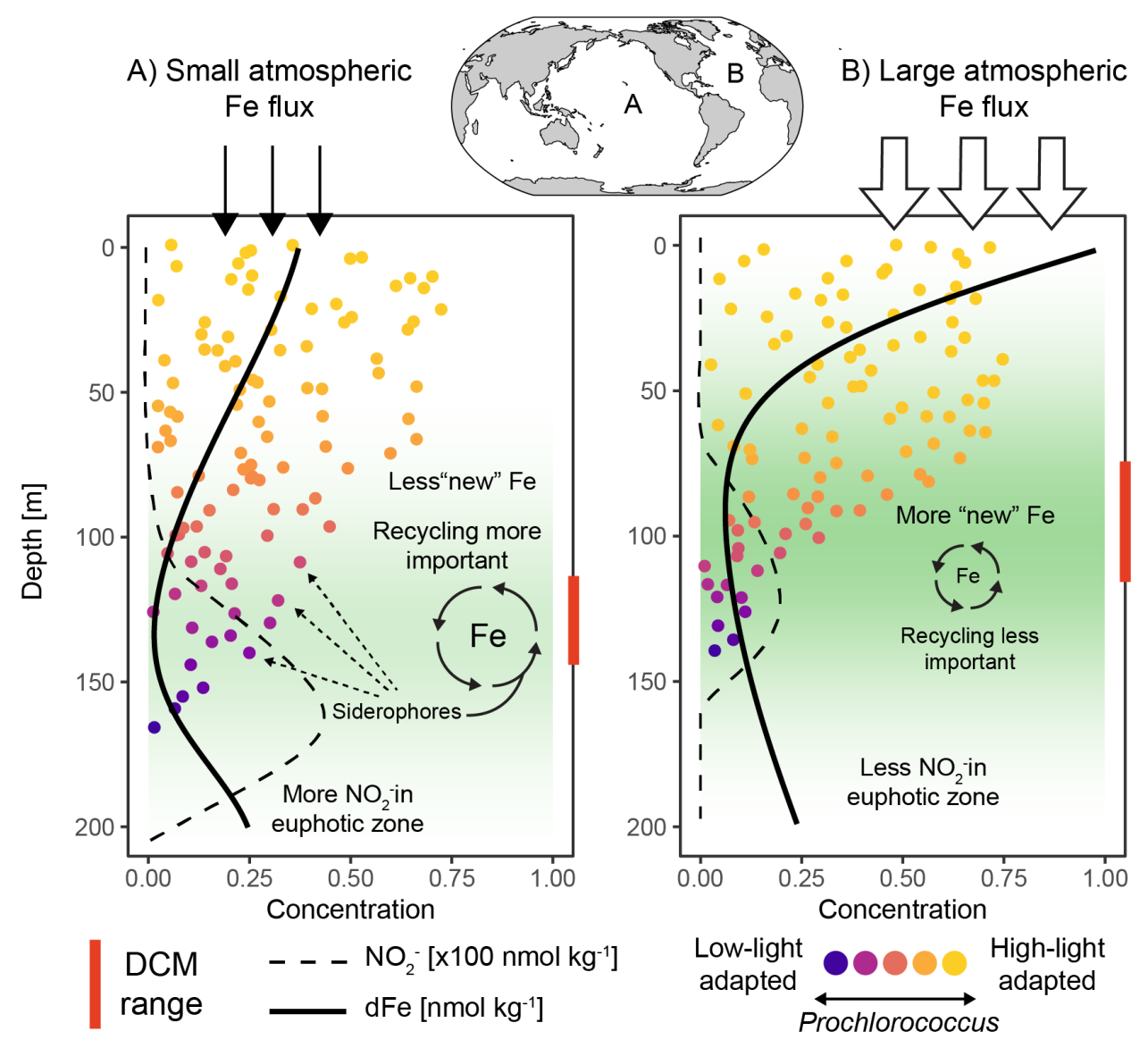

Figure 7. Biogeochemical drivers of Prochlorococcus siderophore uptake

Differences in picocyanobacteria siderophore use between the Pacific and Atlantic ocean. The total abundance of Prochlorococcus is proportional to the number of points at each depth, while color represents high-light and low-light adaptation. DCM = deep chlorophyll maximum layer. 


\section{References}

1. Partensky, F. \& Garczarek, L. Prochlorococcus: Advantages and Limits of Minimalism. Ann. Rev. Mar. Sci. 2, 305-331. ISSN: 1941-1405. eprint: http://dx.doi.org/10.1146/annurev-marine-120308-081034 (2010).

2. Flombaum, P. et al. Present and future global distributions of the marine Cyanobacteria Prochlorococcus and Synechococcus. Proc. Natl. Acad. Sci. U. S. A. 110, 9824-9829. Issn: 0027-8424, 1091-6490 (June 2013).

3. Follows, M. J., Dutkiewicz, S., Grant, S. \& Chisholm, S. W. Emergent biogeography of microbial communities in a model ocean. en. Science 315, 1843-1846. ISSN: 0036-8075, 1095-9203 (Mar. 2007).

4. Biller, S. J., Berube, P. M., Lindell, D. \& Chisholm, S. W. Prochlorococcus: the structure and function of collective diversity. Nat. Rev. Microbiol. 13, 13-27. Issn: 1740-1526 (Dec. 2014).

5. Kashtan, N. et al. Single-cell genomics reveals hundreds of coexisting subpopulations in wild Prochlorococcus. Science 344, 416-420. ISSN: 0036-8075, 1095-9203 (2014).

6. Tagliabue, A. et al. The integral role of iron in ocean biogeochemistry. en. Nature 543, 51-59. ISSN: 0028-0836, 1476-4687 (Mar. 2017).

7. Gledhill, M. \& van den Berg, C. M. G. Determination of complexation of iron(III) with natural organic complexing ligands in seawater using cathodic stripping voltammetry. Mar. Chem. 47, 41-54. ISSN: 0304-4203 (Sept. 1994).

8. Rue, E. L. \& Bruland, K. W. The role of organic complexation on ambient iron chemistry in the equatorial Pacific Ocean and the response of a mesoscale iron addition experiment. Limnol. Oceanogr., 901-910. ISSN: 0024-3590 (1997).

9. Hassler, C. S., van den Berg, C. M. G. \& Boyd, P. W. Toward a Regional Classification to Provide a More Inclusive Examination of the Ocean Biogeochemistry of Iron-Binding Ligands. Frontiers in Marine Science 4, 19. ISSN: 2296-7745 (2017).

10. Gledhill, M. \& Buck, K. N. The organic complexation of iron in the marine environment: a review. Front. Microbiol. 3, 69. ISSN: 1664-302X (Jan. 2012).

11. Bundy, R. M. et al. Distinct Siderophores Contribute to Iron Cycling in the Mesopelagic at Station ALOHA. Frontiers in Marine Science 5, 61. ISSN: 2296-7745 (2018).

12. Boiteau, R. M. et al. Siderophore-based microbial adaptations to iron scarcity across the eastern Pacific Ocean. en. Proc. Natl. Acad. Sci. U. S. A. Issn: 0027-8424, 1091-6490 (Dec. 2016).

13. Shaked, Y. \& Lis, H. Disassembling iron availability to phytoplankton. Front. Microbiol. 3, 123. ISSN: 1664-302X (Jan. 2012).

14. Morrissey, J. \& Bowler, C. Iron utilization in marine cyanobacteria and eukaryotic algae. Front. Microbiol. 3, 43. ISSN: 1664-302X (Jan. 2012).

15. Hogle, S. L., Cameron Thrash, J., Dupont, C. L. \& Barbeau, K. A. Trace metal acquisition by marine heterotrophic bacterioplankton with contrasting trophic strategies. Appl. Environ. Microbiol. 82, 1613-1624. ISSN: 0099-2240, 1098-5336 (Jan. 2016).

16. Hopkinson, B. \& Barbeau, K. Iron transporters in marine prokaryotic genomes and metagenomes. Environ. Microbiol. 14, 114-128. ISSN: 1462-2912, 1462-2920 (Jan. 2012).

17. Webb E. A., Moffett J. W. \& Waterbury J. B. Iron Stress in Open-Ocean Cyanobacteria (Synechococcus, Trichodesmium, andCrocosphaera spp.): Identification of the IdiA Protein. Appl. Environ. Microbiol. 67, 5444-5452. ISSN: 0099-2240 (Dec. 2001).

18. Hopkinson, B. M. \& Morel, F. M. M. The role of siderophores in iron acquisition by photosynthetic marine microorganisms. Biometals 22, 659-669. IssN: 0966-0844, 1572-8773 (Aug. 2009).

19. Malmstrom, R. R. et al. Ecology of uncultured Prochlorococcus clades revealed through single-cell genomics and biogeographic analysis. ISME J. 7, 184-198. ISSN: 1751-7362, 1751-7370 (Jan. 2013). 
20. Ustick, L. J. et al. Metagenomic analysis reveals global-scale patterns of ocean nutrient limitation. en. Science 372, 287-291. ISSN: 0036-8075, 1095-9203 (Apr. 2021).

21. Garcia, C. A. et al. Linking regional shifts in microbial genome adaptation with surface ocean biogeochemistry. en. Philos. Trans. R. Soc. Lond. B Biol. Sci. 375, 20190254. ISSN: 0962-8436, 1471-2970 (May 2020).

22. Hogle, S. L. et al. Pervasive iron limitation at subsurface chlorophyll maxima of the California Current. en. Proc. Natl. Acad. Sci. U. S. A. 115, 13300-13305. Issn: 0027-8424, 1091-6490 (Dec. 2018).

23. Hawco, N. J., Fu, F., Yang, N., Hutchins, D. A. \& John, S. G. Independent iron and light limitation in a low-light-adapted Prochlorococcus from the deep chlorophyll maximum. en. ISME J. ISSN: 1751-7362, 1751-7370 (Sept. 2020).

24. Biller, S. J. et al. Marine microbial metagenomes sampled across space and time. Scientific Data 5, 180176 (Sept. 2018).

25. Pesant, S. et al. Open science resources for the discovery and analysis of Tara Oceans data. en. Sci Data 2, 150023. ISSN: 2052-4463 (May 2015).

26. Berube, P. M. et al. Single cell genomes of Prochlorococcus, Synechococcus, and sympatric microbes from diverse marine environments. Scientific Data 5, 180154 (Sept. 2018).

27. Biller, S. J. et al. Genomes of diverse isolates of the marine cyanobacterium Prochlorococcus. Sci Data 1, 140034. ISSN: 2052-4463 (Sept. 2014).

28. Karsenti, E. et al. A holistic approach to marine eco-systems biology. en. PLoS Biol. 9, e1001177. ISSN: 1544-9173, 1545-7885 (Oct. 2011).

29. Schlitzer, R. et al. The GEOTRACES Intermediate Data Product 2017. Chem. Geol. 493, $210-223$. ISSN: 0009-2541 (Aug. 2018).

30. Salt, L. A., van Heuven, S. M. A. C., Claus, M. E., Jones, E. M. \& de Baar, H. J. W. Rapid acidification of mode and intermediate waters in the southwestern Atlantic Ocean. en. Biogeosciences 12, 1387-1401. ISSN: 1726-4170 (Mar. 2015).

31. Rijkenberg, M. J. A. et al. The distribution of dissolved iron in the West Atlantic Ocean. en. PLoS One 9, e101323. ISSN: 1932-6203 (June 2014).

32. Wyatt, N. J. et al. Biogeochemical cycling of dissolved zinc along the GEOTRACES South Atlantic transect GA10 at $40^{\circ} \mathrm{S}$ : Dissolved zinc in the Atlantic at $40^{\circ} \mathrm{S}$. Global Biogeochem. Cycles. NATO Conference Series IV; Marine Sciences 28, 44-56. ISSN: 0886-6236 (Jan. 2014).

33. Ashkezari, M. D. et al. Simons Collaborative Marine Atlas Project (Simons CMAP ): An open-source portal to share, visualize, and analyze ocean data. en. Limnol. Oceanogr. Methods 19, 488-496. ISSN: 1541-5856 (July 2021).

34. Acker, M. et al. Phosphonate production by marine microbes: exploring new sources and potential function en. Nov. 2020.

35. Becker, J. W., Hogle, S. L., Rosendo, K. \& Chisholm, S. W. Co-culture and biogeography of Prochlorococcus and SAR11. en. ISME J. 13, 1506-1519. ISSN: 1751-7362, 1751-7370 (Feb. 2019).

36. Malmstrom, R. R. et al. Temporal dynamics of Prochlorococcus ecotypes in the Atlantic and Pacific oceans. en. ISME J. 4, 1252-1264. ISSN: 1751-7362, 1751-7370 (Oct. 2010).

37. Fitzsimmons, J. N. et al. Daily to decadal variability of size-fractionated iron and iron-binding ligands at the Hawaii Ocean Time-series Station ALOHA. Geochim. Cosmochim. Acta 171, 303-324. ISSN: 0016-7037 (Dec. 2015).

38. Buck, K. N., Sohst, B. \& Sedwick, P. N. The organic complexation of dissolved iron along the U.S. GEOTRACES (GA03) North Atlantic Section. Deep Sea Res. Part 2 Top. Stud. Oceanogr. 116, 152-165. ISSN: 0967-0645 (June 2015). 
39. Mawji, E. et al. Hydroxamate siderophores: occurrence and importance in the Atlantic Ocean. Environ. Sci. Technol. 42, 8675-8680. ISSN: 0013-936X (Dec. 2008).

40. Buck, K. N. \& Bruland, K. W. The physicochemical speciation of dissolved iron in the Bering Sea, Alaska. Limnol. Oceanogr. 52, 1800-1808. ISSN: 0024-3590 (2007).

41. Boiteau, R. M., Fitzsimmons, J. N., Repeta, D. J. \& Boyle, E. a. Detection of iron ligands in seawater and marine cyanobacteria cultures by high-performance liquid chromatography-inductively coupled plasma-mass spectrometry. Anal. Chem. 85, 4357-4362. ISSN: 0003-2700, 1520-6882 (May 2013).

42. Blin, K. et al. antiSMASH 5.0: updates to the secondary metabolite genome mining pipeline. en. Nucleic Acids Res. 47, W81-W87. ISSN: 0305-1048, 1362-4962 (July 2019).

43. Menzel, P., Ng, K. L. \& Krogh, A. Fast and sensitive taxonomic classification for metagenomics with Kaiju. Nat. Commun. 7, 11257. ISSN: 2041-1723 (Apr. 2016).

44. Wright, M. \& Ziegler, A. ranger: A Fast Implementation of Random Forests for High Dimensional Data in C++ and R. Journal of Statistical Software, Articles 77, 1-17. ISSN: 1548-7660 (2017).

45. Jolliffe, I. T. Principal Component Analysis en. ISBN: 9783540962694 (Springer-Verlag, 1986).

46. Kursa, M. \& Rudnicki, W. Feature Selection with the Boruta Package. Journal of Statistical Software, Articles 36, 1-13. ISSN: 1548-7660 (2010).

47. Milligan, A. J. \& Harrison, P. J. Effects of non-steady-state iron limitation on nitrogen assimilatory enzymes in the marine diatom Thalassiosira weissflogii (Bacillariophyceae). J. Phycol. 36, 78-86. ISSN: 0022-3646, 1529-8817 (Feb. 2000).

48. Lomas, M. W. \& Lipschultz, F. Forming the primary nitrite maximum: Nitrifiers or phytoplankton? Limnol. Oceanogr. 51, 2453-2467. ISSN: 0024-3590 (Sept. 2006).

49. Lenth, R. emmeans: Estimated Marginal Means, aka Least-Squares Means 2020.

50. Ahlgren, N. A., Belisle, B. S. \& Lee, M. D. Genomic mosaicism underlies the adaptation of marine Synechococcus ecotypes to distinct oceanic iron niches. en. Environ. Microbiol. ISSN: 1462-2912, 1462-2920 (Dec. 2019).

51. Pinedo-González, P. et al. Anthropogenic Asian aerosols provide Fe to the North Pacific Ocean. en. Proc. Natl. Acad. Sci. U. S. A. Issn: 0027-8424, 1091-6490 (Oct. 2020).

52. Martiny, A. C., Coleman, M. L. \& Chisholm, S. W. Phosphate acquisition genes in Prochlorococcus ecotypes: evidence for genome-wide adaptation. Proc. Natl. Acad. Sci. U. S. A. 103, 12552-12557. ISSN: 0027-8424 (Aug. 2006).

53. Coleman, M. L. \& Chisholm, S. W. Ecosystem-specific selection pressures revealed through comparative population genomics. Proc. Natl. Acad. Sci. U. S. A. 107, 18634-18639. Issn: 0027-8424, 1091-6490 (Oct. 2010).

54. Berube, P. M., Rasmussen, A., Braakman, R., Stepanauskas, R. \& Chisholm, S. W. Emergence of trait variability through the lens of nitrogen assimilation in Prochlorococcus. en. Elife 8. ISSN: 2050-084X (Feb. 2019).

55. Olgun, N. et al. Surface ocean iron fertilization: The role of airborne volcanic ash from subduction zone and hot spot volcanoes and related iron fluxes into the Pacific Ocean. en. Global Biogeochem. Cycles 25. ISSN: 0886-6236, 1944-9224 (Dec. 2011).

56. Manck, L. E. et al. Petrobactin, a siderophore produced by Alteromonas, mediates community iron acquisition in the global ocean. en. ISME J., 1-12. ISSN: 1751-7362 (Aug. 2021).

57. Sohm, J. A. et al. Co-occurring Synechococcus ecotypes occupy four major oceanic regimes defined by temperature, macronutrients and iron. ISME J. 10, 333-345. ISSN: 1751-7362, 1751-7370 (Feb. 2016). 
58. Mackey, K. R. M., Post, A. F., McIlvin, M. R. \& Saito, M. A. Physiological and proteomic characterization of light adaptations in marine Synechococcus. en. Environ. Microbiol. 19, 2348-2365. ISSN: 1462-2912, 1462-2920 (June 2017).

59. Raven, J. A. Predictions of Mn and Fe use efficiencies of phototrophic growth as a function of light availability for growth and of C assimilation pathway. New Phytol. 116, 1-18. ISSN: 0028-646X, 1469-8137 (Sept. 1990).

60. Sunda, W. G. \& Huntsman, S. A. Interrelated influence of iron, light and cell size on marine phytoplankton growth. Nature 390, 389-392. ISSN: 0028-0836, 1476-4687 (Nov. 1997).

61. Hawco, N. J. et al. Iron depletion in the deep chlorophyll maximum: mesoscale eddies as natural iron fertilization experiments July 2021.

62. Karl, D. M. \& Church, M. J. Microbial oceanography and the Hawaii Ocean Time-series programme. en. Nat. Rev. Microbiol. 12, 699-713. ISSN: 1740-1526, 1740-1534 (Oct. 2014).

63. Neuer, S. et al. Differences in the biological carbon pump at three subtropical ocean sites. Geophys. Res. Lett. 29, 32-1-32-4. ISSN: 0094-8276 (Sept. 2002).

64. Giovannoni, S. J. \& Vergin, K. L. Seasonality in Ocean Microbial Communities. Science 335, 671-676. ISSN: 0036-8075 (Feb. 2012).

65. Jickells, T. \& Moore, C. M. The Importance of Atmospheric Deposition for Ocean Productivity. Annu. Rev. Ecol. Evol. Syst. 46, 481-501. Issn: 1543-592X (Dec. 2015).

66. Browning, T. J. et al. Nutrient co-limitation at the boundary of an oceanic gyre. en. Nature. ISSN: 0028-0836, 1476-4687 (Nov. 2017).

67. Louropoulou, E. et al. Heme b distributions through the Atlantic Ocean: evidence for "anemic" phytoplankton populations. en. Sci. Rep. 10, 4551. ISSN: 2045-2322 (Mar. 2020).

68. Rijkenberg, M. J. A. et al. The distribution of dissolved iron in the West Atlantic Ocean. en. PLoS One 9, e101323 (June 2014).

69. Mark Moore, C. Diagnosing oceanic nutrient deficiency. en. Philos. Trans. R. Soc. Lond. A 374, 20150290. ISSN: 0080-4614 (Nov. 2016).

70. Moore, C. M. et al. Processes and patterns of oceanic nutrient limitation. Nat. Geosci. 6, 701-710. ISSN: 1752-0894, 1752-0908 (Mar. 2013).

71. Moore, J. K., Doney, S. C. \& Lindsay, K. Upper ocean ecosystem dynamics and iron cycling in a global three-dimensional model. en. Global Biogeochem. Cycles 18. ISSN: 0886-6236, 1944-9224 (Dec. 2004).

72. Rafter, P. A., Sigman, D. M. \& Mackey, K. R. M. Recycled iron fuels new production in the eastern equatorial Pacific Ocean. en. Nat. Commun. 8, 1100. ISSN: 2041-1723 (Oct. 2017).

73. Tagliabue, A. et al. The interplay between regeneration and scavenging fluxes drives ocean iron cycling. en. Nat. Commun. 10, 4960. ISSN: 2041-1723 (Oct. 2019).

74. Ferreira, D. et al. Atlantic-Pacific Asymmetry in Deep Water Formation. Annu. Rev. Earth Planet. Sci. 46, 327-352. ISSN: 0084-6597 (May 2018).

75. Jickells, T. D., Baker, A. R. \& Chance, R. Atmospheric transport of trace elements and nutrients to the oceans. en. Philos. Trans. R. Soc. Lond. A 374, 20150286. ISSN: 0080-4614 (Nov. 2016).

76. Rusch, D. B., Martiny, A. C., Dupont, C. L., Halpern, A. L. \& Venter, J. C. Characterization of Prochlorococcus clades from iron-depleted oceanic regions. Proc. Natl. Acad. Sci. U. S. A. 107, 16184-16189. ISSN: 0027-8424 (2010).

77. Dutkiewicz, S., Ward, B. A., Monteiro, F. \& Follows, M. J. Interconnection of nitrogen fixers and iron in the Pacific Ocean: Theory and numerical simulations. Global Biogeochem. Cycles 26, GB1012. ISSN: 0886-6236, 1944-9224 (Mar. 2012).

78. Resing, J. A. et al. Basin-scale transport of hydrothermal dissolved metals across the South Pacific Ocean. Nature 523, 200-203. ISSN: 0028-0836, 1476-4687 (July 2015). 
79. Sela, I., Wolf, Y. I. \& Koonin, E. V. Theory of prokaryotic genome evolution. en. Proc. Natl. Acad. Sci. U. S. A. 113, 11399-11407. ISSN: 0027-8424, 1091-6490 (Oct. 2016).

80. Zakem, E. J. et al. Ecological control of nitrite in the upper ocean. en. Nat. Commun. 9, 1206. ISSN: 2041-1723 (Mar. 2018).

81. Lauderdale, J. M., Braakman, R., Forget, G., Dutkiewicz, S. \& Follows, M. J. Microbial feedbacks optimize ocean iron availability. en. Proc. Natl. Acad. Sci. U. S. A. IsSN: 0027-8424, 1091-6490 (Feb. 2020). 